\title{
Pollution discharge Scenario of Dyeing Industries along Dombivali Industrial Belt of Mumbai, India
}

\author{
P. U. Singare ${ }^{1, *}$, S. S. Dhabarde $e^{2,3}$ \\ ${ }^{1}$ Department of Chemistry, Bhavan's College, Munshi Nagar, Andheri (West), Mumbai, \\ Maharashtra 400058, India \\ ${ }^{2}$ Department of Chemistry, K.V. Pendharkar College, Dombivali (East), Dist. Thane, \\ Maharashtra 421201, India \\ ${ }^{3}$ Department of Chemistry, Pacific University of Higher Education \& Research University, \\ Udaipur, Rajasthan, India \\ *E-mail address: pravinsingare@gmail.com
}

\begin{abstract}
The paper deals with monitoring of pollution arising due to dyeing industries located along the Dombivali industrial belt of Mumbai, India. The study was carried for the period of one year from June, 2012 to May, 2013 to study the level of toxic heavy metals and the physico-chemical properties of waste water effluents discharged from the above industries. The concentrations of $\mathrm{Cu}, \mathrm{Ni}, \mathrm{Cr}, \mathrm{Pb}$, $\mathrm{Fe}$ and $\mathrm{Zn}$ were found to be maximum of $44.78,2.50,1.75,1.45,64.22$ and $13.22 \mathrm{ppm}$ respectively in the industrial waste water effluent.It was observed that the $\mathrm{pH}$ value was maximum of 12.30 in the month of June while the conductivity was found to be maximum of $48000 \mu \mathrm{mhos} / \mathrm{cm}$ in the month of February. The majority of physco-chemical parameters like alkalinity, salinity and total solid content (TS) were observed to be maximum in the month of February having values of 3578, 44.08 and 40450 ppm respectively. The high cyanide $(0.18 \mathrm{ppm})$ and phosphate $(112.90 \mathrm{ppm})$ levels were reported in the effluents released during the month of March. The industrial effluent released in the month of June was reported to have high hardness, chloride and COD content having the values of 743, 2381, 8957 ppm respectively; while the DO content was found to be very low of $2.77 \mathrm{ppm}$. The BOD content in the effluents was found to be maximum of $603 \mathrm{ppm}$ in the month of October. The results of present study indicates that the existing situation if mishandled can cause irreparable ecological harm in the long term well masked by short term economic prosperity due to extensive industrial growth.
\end{abstract}

Keywords: industrial effluents; physico-chemical properties; heavy metals; dyeing industries; Dombivali industrial belt; Mumbai

\section{INTRODUCTION}

With the rapid industrialization in the country, environment pollution by industrial waste has increased tremendously [1-3]. The discharge of waste water from industries such as dyeing, tanneries, pulp and paper, textile, petroleum, chemical industries etc. pollute water bodies [4]. Nature has an amazing ability to cope up with small amount of water wastes and pollution, but it would be hazardous or harmful if billions of gallons of waste water produced everyday are not treated before releasing them back to the environment. The quantities and characteristics of discharged effluent vary from industry to industry depending on the water 
consumption and average daily product [5]. Wastewaters contaminated by dyes represent a relevant issue associated with several industries. Dyes, even at very low concentrations, reduce wastewater transparency and oxygen solubility and are often toxic and recalcitrant; moreover, these chemicals are toxic, carcinogenic or mutagenic for various organisms [6]. In addition, coloured streams are characterized by large fluctuations of composition, $\mathrm{pH}$ and temperature [7]. Central Pollution Control Board has listed the dye and dye intermediates industry as one of the heavily polluting industries [8].

They are thus, a potent hazard to the natural sources like soil, water, flora, fauna, livestock and human population [6].These industries use a variety of chemicals and azo dyes (direct, reactive, rapid, mordant and premetalised etc.) during processing and finishing of raw materials. The workers in these industries are exposed to such dyes with no control over the length and frequency of exposure. Further, a huge volume of mostly untreated textile dye wastewater is released into surface waters through the drainage systems, seep into the ground water and adjoining water bodies. Industrial effluents contain dyes, aniline, caustic soda, acids, bleaching powder, heavy metal ions etc. Most of the heavy metals are essential for growth of organisms but are only required in low concentrations [9].

The increasing concentration of heavy metals leads to bioaccumulation of metals in fauna and flora. Heavy metals are not biodegradable so they accumulate in primary organs in the body and over time begin to fester, leading to various symptoms of diseases [10]. Several studies have been conducted by different scientists on adverse effects of textile effluents on soil and water environment $[11,12]$. Untreated or incompletely treated textile effluent can be harmful to both aquatic and terrestrial life by adversely affecting on the natural ecosystem and long term health effects [5]. The physico-chemical techniques used for removing pollutants from the environment are inefficient, costly, of limited applicability, and sometimes producing large amounts of toxic waste which is difficult to dispose off or form hazardous by-product.

Considering the environmental impact of pollution arising due to dyeing industries at global level in general and India in particular, in the present investigation attempts was made to carry out the comprehensive survey of pollution monitoring of the effluents released from such industries located in Dombivali MIDC industrial belt which is considered to be one of the most polluted industrial belts of Mumbai.

\section{EXPERIMENTAL}

\section{1. Study area}

The Dombivali industrial area was established by Maharashtra Industrial Development Corporation (M.I.D.C) in 1964. The industrial belt occupies an area of about 347.88 hector, is located in south of Ulhas River and about $45.00 \mathrm{~km}$ from Mumbai international airport. There are about 30 highly polluting small /medium/ large scale chemical industries located in this industrial belt. Quantity of industrial effluent generated in the industrial area is about 14 MLD, which is finally discharged into the creek through open drainages which was passing through residential area [13].

\section{2. Climatic condition}

Dombivali enjoys a tropical climate with mean annual temperature of $24.3{ }^{\circ} \mathrm{C}(\mathrm{min})$ to $32.9^{\circ} \mathrm{C}(\max )$. The hottest and driest part of the year is April-May, when temperature rises to $38.0^{\circ} \mathrm{C}$. The humidity is usually in the range of 58 to $84 \%$ and sea breeze in the evening 
hours is a blessing to combat the high temperature and humidity during summer months. The average southwest monsoon rainfall is in the range of $1850 \mathrm{~mm}$ to $2000 \mathrm{~mm}$. The average annual rainfall in the region is the range from 1286 to $1233 \mathrm{~mm}$ [13].

\section{3. Requirements}

All the chemicals and reagent used for analysis were of analytical reagent grade. The glasswares used in the analysis were washed with distilled de-ionized water; the pipettes and burette were rinsed with the experimental solution before final use.

\section{4. Industrial Effluent Sampling and Preservation}

The industrial waste water effluent samples were collected randomly twice in a month in morning, afternoon and evening session from three representative dyeing units of Dombivali industrial belt of Mumbai. The samples were collected every month from June, 2012 to May, 2013. Polythene bottles of $2.5 \mathrm{~L}$ and $2.0 \mathrm{~L}$ were used to collect the grab water samples (number of samples collected, $n=20$ ). The bottles were thoroughly cleaned with hydrochloric acid, washed with tape water to render free of acid, washed with distilled water twice, again rinsed with the water sample to be collected and then filled up the bottle with the sample leaving only a small air gap at the top. The sample bottles were stoppard and sealed with paraffin wax.

\section{5. Physico-chemical Study}

The samples were collected were analyzed for $\mathrm{pH}$, conductivity, alkalinity, hardness, salinity, chloride, cyanide, phosphate content, Total Dissolved Solids (T.D.S), Total Suspended Solids (T.S.S), Total Solids (T.S), Dissolved Oxygen (D.O), Bio-chemical Oxygen Demand (B.O.D) and Chemical Oxygen Demand (C.O.D) values.

The techniques and methods followed for collection, preservation, analysis and interpretation are those given by Rainwater and Thatcher [14], Brown et al. [15], I.C.M.R [16], Hem [17] and A.P.H.A [18].

\section{6. Heavy Metal Analysis by AAS Technique}

Water samples $(500 \mathrm{~mL})$ were filtered using Whatman No. $41(0.45 \mu \mathrm{m}$ pore size $)$ filter paper for estimation of dissolved metal content. Filtrate $(500 \mathrm{~mL})$ was preserved with $2 \mathrm{~mL}$ nitric acid to prevent the precipitation of metals. The samples were concentrated on a water bath depending on the suspected level of the metals [19].

The analysis for the majority of the trace metals like copper $(\mathrm{Cu})$, nickel $(\mathrm{Ni})$, chromium $(\mathrm{Cr})$, lead $(\mathrm{Pb})$, iron $(\mathrm{Fe})$ and zinc $(\mathrm{Zn})$ was done by Perkin Elmer ASS-280 Flame Atomic Absorption Spectrophotometer. The calibration curves were prepared separately for all the metals by running different concentrations of standard solutions.

A reagent blank sample was run throughout the method, and the blank readings were subtracted from the samples to correct for reagent impurities and other sources of errors from the environment. Average values of three replicates were taken for each determination. 


\section{RESULTS AND DISCUSSION}

The experimentally measured pollution data on heavy metal content and physicochemical properties of industrial waste water effluents released from dyeing industries located along the Dombivali industrial belt of Mumbai, India is presented in Tables 1 and 2.

Table 1. Physico-chemical properties of the effluents released from dyeing industries located along Dombivali Industrial Belt of Mumbai, India.

\begin{tabular}{|c|c|c|c|c|c|c|c|c|c|c|c|c|}
\hline 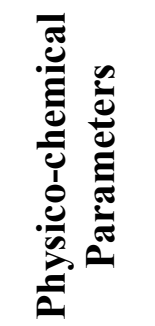 & 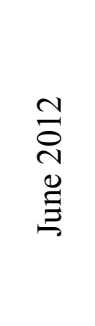 & 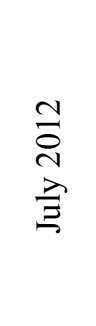 & 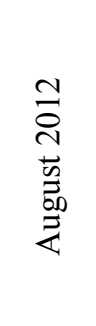 & 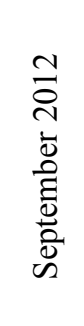 & 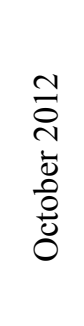 & 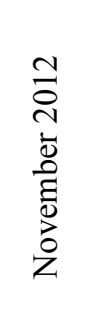 & 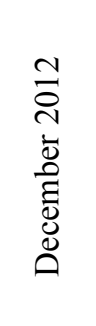 & 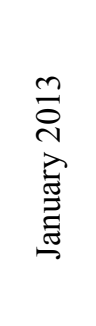 & 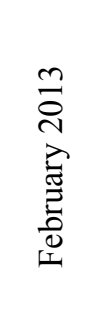 & 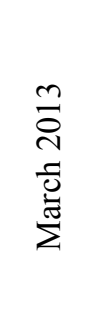 & 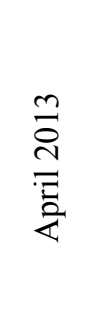 & $\begin{array}{l}\frac{n}{2} \\
\stackrel{N}{2} \\
\sum_{i}^{\pi}\end{array}$ \\
\hline $\mathrm{pH}$ & 12.30 & 10.70 & 11.43 & 11.93 & 8.18 & 9.45 & 8.63 & 9.70 & 9.90 & 11.25 & 9.86 & 10.50 \\
\hline $\begin{array}{l}\text { Conductivity } \\
(\mu \mathrm{mhos} / \mathrm{cm})\end{array}$ & 21300 & 18990 & 14751 & 9548 & 6952 & 8939 & 13990 & 16574 & 48000 & 39854 & 35850 & 44696 \\
\hline $\begin{array}{l}\text { Alkalinity } \\
\text { (ppm) }\end{array}$ & 157 & 295 & 360 & 478 & 235 & 547 & 698 & 1279 & 3578 & 3251 & 2981 & 2391 \\
\hline $\begin{array}{l}\text { Hardness } \\
(\mathrm{ppm})\end{array}$ & 743 & 570 & 457 & 398 & 273 & 349 & 296 & 281 & 297 & 357 & 476 & 328 \\
\hline $\begin{array}{l}\text { Salinity } \\
\text { (ppm) }\end{array}$ & 6.09 & 6.40 & 4.87 & 5.39 & 4.90 & 1.98 & 2.67 & 8.76 & 44.08 & 39.40 & 34.29 & 40.75 \\
\hline $\mathrm{Cl}^{-}(\mathrm{ppm})$ & 2381 & 1861 & 1342 & 1091 & 912 & 1377 & 1641 & 2147 & 2220 & 2306 & 2266 & 2351 \\
\hline $\mathrm{CN}^{-}(\mathrm{ppm})$ & 0.01 & 0.05 & 0.02 & 0.03 & 0.10 & 0.17 & 0.13 & 0.12 & 0.15 & 0.18 & 0.13 & 0.11 \\
\hline $\begin{array}{l}\text { Phosphates } \\
\text { (ppm) }\end{array}$ & 4.80 & 7.60 & 5.76 & 6.60 & 7.66 & 8.98 & 7.67 & 10.60 & 108.54 & 112.90 & 85.80 & 75.23 \\
\hline TDS (ppm) & 19670 & 15430 & 9457 & 8943 & 4860 & 6789 & 8756 & 9395 & 34120 & 32500 & 29760 & 30540 \\
\hline TSS (ppm) & 220 & 543 & 470 & 859 & 1880 & 3560 & 5601 & 6111 & 6330 & 5478 & 4065 & 5300 \\
\hline TS (ppm) & 19890 & 15973 & 9927 & 9802 & 6740 & 10349 & 14357 & 15506 & 40450 & 37978 & 33825 & 35840 \\
\hline D.O (ppm) & 2.77 & 4.00 & 3.99 & 4.50 & 3.05 & 3.50 & 3.89 & 3.80 & 3.91 & 3.01 & 4.10 & 2.99 \\
\hline $\begin{array}{l}\text { B.O.D } \\
\text { (ppm) }\end{array}$ & 237 & 342 & 548 & 439 & 603 & 599 & 589 & 602 & 588 & 439 & 457 & 590 \\
\hline $\begin{array}{l}\text { C.O.D } \\
\text { (ppm) }\end{array}$ & 8957 & 6780 & 4388 & 5491 & 4053 & 6098 & 4098 & 6578 & 6666 & 7690 & 8560 & 7980 \\
\hline
\end{tabular}


Table 2. Heavy Metal content in the effluents released from dyeing industries located along Dombivali Industrial Belt of Mumbai, India.

\begin{tabular}{|c|c|c|c|c|c|c|c|c|c|c|c|c|}
\hline 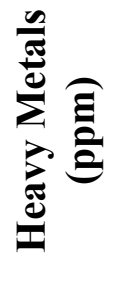 & $\begin{array}{l}\stackrel{N}{D} \\
\stackrel{N}{ } \\
\stackrel{\Xi}{\Xi} \\
\end{array}$ & 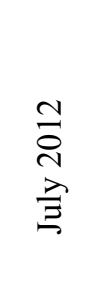 & 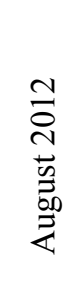 & 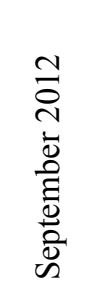 & 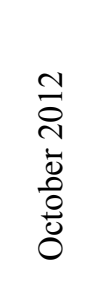 & 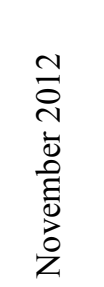 & 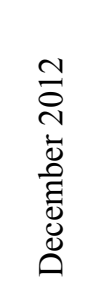 & 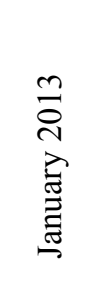 & 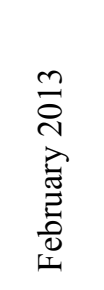 & $\begin{array}{l}\stackrel{m}{0} \\
\text { N } \\
\frac{0}{0} \\
0 \\
\Sigma\end{array}$ & 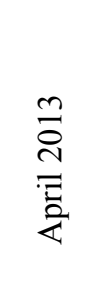 & $\begin{array}{l}\stackrel{m}{\sigma} \\
\stackrel{\sim}{N} \\
\stackrel{\Xi}{\Sigma}\end{array}$ \\
\hline $\mathrm{Cu}$ & 0.17 & 0.98 & 2.59 & 4.90 & 14.53 & 15.67 & 25.68 & 35.34 & 44.78 & 44.00 & 38.96 & 42.75 \\
\hline $\mathrm{Ni}$ & 0.45 & 0.43 & 0.42 & 0.54 & 0.58 & 0.72 & 0.69 & 0.73 & 0.75 & 0.95 & 1.05 & 2.50 \\
\hline $\mathrm{Cr}$ & 0.97 & 1.04 & 1.23 & 1.30 & 1.33 & 1.70 & 1.65 & 1.50 & 1.72 & 1.62 & 1.50 & 1.75 \\
\hline $\mathrm{Pb}$ & 0.92 & 0.95 & 0.97 & 0.99 & 1.00 & 1.23 & 1.45 & 1.39 & 1.44 & 1.41 & 1.24 & 1.12 \\
\hline $\mathrm{Fe}$ & 2.05 & 5.98 & 4.75 & 3.39 & 44.34 & 50.43 & 60.38 & 52.29 & 64.22 & 55.60 & 45.46 & 63.5 \\
\hline $\mathrm{Zn}$ & 13.22 & 12.74 & 7.97 & 8.70 & 6.14 & 8.00 & 8.06 & 7.78 & 8.03 & 9.68 & 11.85 & 10.54 \\
\hline
\end{tabular}

Trace elements are those elements which are present in relatively low concentration of less than few ppm. Among the special group of trace elements are the heavy metals which are having the potential to create health hazards among humans, plants and other aquatic biological life. Under the group of heavy metals are $\mathrm{Cr}, \mathrm{Ni}, \mathrm{Zn}, \mathrm{Cu}, \mathrm{Pb}$ and $\mathrm{Fe}$. They are classified under the group of heavy metals because in metallic form they have the densities higher than $4 \mathrm{~g} / \mathrm{cm}^{3}$. The $\mathrm{Cu}$ content in the industrial effluent was found to be minimum of $0.17 \mathrm{ppm}$ in the month of June and maximum of $44.78 \mathrm{ppm}$ in the month of February. The values reported were above the permissible limit of $0.05 \mathrm{ppm}$ set by $W . H . O$ and $1.0 \mathrm{ppm}$ as per the USPH standards. The Ni content in the effluent released was in the range of 0.42 and $2.50 \mathrm{ppm}$. The overall experimental observed $\mathrm{Ni}$ concentration was above the maximum tolerable limit of $0.1 \mathrm{ppm}$ set by W.H.O.

The $\mathrm{Cr}$ content in the industrial effluent was found to be minimum of $0.97 \mathrm{ppm}$ in the month of June and maximum of $1.75 \mathrm{ppm}$ in the month of May. The reported concentration level of $\mathrm{Cr}$ was higher than the maximum permissible limit of $0.05 \mathrm{ppm}$ set by W.H.O [20]. The $P b$ content in the effluent released was in the range of 0.92 and $1.45 \mathrm{ppm}$, this values were extremely higher than the general standard limit of $0.1 \mathrm{ppm}$ lead set for effluents discharge in inland surface water [21]. The Fe content in the industrial effluent was found to be minimum of $2.05 \mathrm{ppm}$ in the month of June and maximum of $64.22 \mathrm{ppm}$ in the month of February. The observed levels of $\mathrm{Fe}$ (except in the month of June) were above the permissible limit of $3.0 \mathrm{ppm}$ iron set for effluents discharge in inland surface water [21]. The $\mathrm{Zn}$ content in the effluent released was in the range of 6.14 and $13.22 \mathrm{ppm}$. 
The concentrations of $Z n$ in the industrial effluent released throughout the year were extremely higher than the general standard limit of $5.0 \mathrm{ppm} Z n$ set for effluents discharge in inland surface water [21].

In any environmental monitoring study related to pollution of surface water, physicochemical parameters gives valuable information regarding the pollution load. It is found that most of the industries in India are located near the water bodies because of their extensive requirement of water for various industrial activities. The waste water from such industries are generally discharged in drainages which finally enter the nearby water bodies creating extensive pollution creating threat to the aquatic life and health of surrounding human population. The most common physico-chemical parameters are $\mathrm{pH}$, conductivity, hardness, alkalinity, suspended and dissolved solids, BOD, COD and DO.

These parameters generally decide the extent of pollution and help in planning the waste water treatment technology which is to be adopted. In the present investigation it was observed that the $\mathrm{pH}$ value was minimum of 8.18 in the month of October to maximum of 12.30 in the month of June. It is important here to note that the permissible $\mathrm{pH}$ range of inland surface water subjected to pollution load is 5.5 to 9.0 [21-31].

The conductivity of the industrial waste water effluent was found to vary in the range of $6952 \mu \mathrm{mhos} / \mathrm{cm}$ in the month of October to $48000 \mu \mathrm{mhos} / \mathrm{cm}$ in the month of February. The majority of physco-chemical parameters like alkalinity, salinity and total solid content (TS) were observed to be maximum in the month of February having values of 3578, 44.08 and $40450 \mathrm{ppm}$ respectively. The high cyanide $(0.18 \mathrm{ppm})$ and phosphate $(112.90 \mathrm{ppm})$ levels were observed in the effluents released during the month of March. The industrial effluent released in the month of June was reported to have high hardness, chloride and COD content having the values of $743,2381,8957 \mathrm{ppm}$ respectively; while the DO content was found to be very low of $2.77 \mathrm{ppm}$. The BOD content in the effluents was found to be maximum of 603 ppm in the month of October.

\section{CONCLUSION}

Currently, India is considered to be one of attractive destinations for investment in the world economy. Apart from its large domestic consumer base of one billion, it also offers a perfect setting for basing manufacturing and other services to serve the global market owing to its cheap labour.

With the Indian Government making an all out effort to increase Foreign direct investment to USD 50 billion within 5 years, huge investments can also be expected in manufacturing chemicals, pesticides, textiles and every imaginable product; increase in waste output and spread of toxic hotspots across the country.

Around the world as countries are struggling to arrive at an effective regulatory regime to control the discharge of industrial effluents into their ecosystems, Indian economy holds a double edged sword of economic growth and ecosystem collapse. As India moves towards stricter regulation of industrial effluents to control water pollution greater efforts are required to reduce the risk to public health as toxic pollutants which are mainly colourless and odourless can be expected to be released into the ecosystems.

Hence there is a need that each industry should treat their effluents, in accordance with the legal requirements, before discharging these into the streams otherwise 'Polluter pays' principle should be implemented. 


\section{References}

[1] Tiwari P. K., Indian dairy man. 46(10) (1994) 617-624.

[2] Muthuswamy A., Jayabalan N., J. Environ. Biol. 22(4) (2001) 237-247.

[3] Noorjahan C. M., Physicochemical characterization of untreated textile effluent and its effects on biochemical constituents of fresh water fish, tilapia mossambica, Indian Streams Research Journal 1(5) (2011).

[4] Mohan Rao G., Application of treated effluent for irrigation, Water world, Department of Engineering, Rec, Trichy, (1998) 4-13.

[5] Joshi V. J., Santani D. D., Universal Journal of Environmental Research and Technology 2(2) (2012) 93-96.

[6] Mathur N., Bhatnagar P., Journal of Environmental Biology 28(1) (2007) 123-126.

[7] Hai F. I., Yamamoto K., Fukushi K., Crit. Rev. Environ. Sci. Technol. 37 (2007) 315-377.

[8] CPCB (Central Pollution Control Board): Minimal national standards: Dye and dye intermediate industry. Comprehensive Industry Document Series: COINDS/ 34/1990(1990).

[9] Akpoveta O. V., Osakwe S. A., Okoh B. E., Otuya B. O. J. Appl. Sci. Environ. Mangae. 14(4) (2010) 57-60.

[10] Siyanbola T. O., Ajanaku K. O., James O. O., Olugbuyiro J. A. O., Jadekoya J. O., G. J. P \& A Sci. and Tech. 01 (2011) 49-54.

[11] Sponza D. T., Environ. Monit. Assess. 7391 (2002) 41-66.

[12] Chaturvedi R. K., Sharma K. P., Sharma K., Bhardwaj S. M., Subhasini S., Journal of Environmental Pollution 6 (1999) 77-84.

[13] Action Plan for Industrial Cluster "Dombivali”, Maharashtra Pollution Control Board, November 2010. http://www.mpcb.gov.in

[14] Rainwater F. H., Thatcher L. L., U.S. Geol. Surv. Water Supply Papers 1454 (1960) $1-301$.

[15] E. Brown, M. W. Skougstad, M. J. Fishman, 'Methods for collection and analysis of Water samples for dissolved minerals and gases', Techniques of Water Resources Investigations of the U.S. Geological Survey, Vol. 160, Book 5, Chapter A1 (1970).

[16] Indian Council of Medical Research (ICMR) Manual of Standards of Quality for Drinking Water Supplies, (1975).

[17] J. D. Hem, 'Study and Interpretation of Chemical Characteristics of Natural Water', $3^{\text {rd }}$ ed., U.S. Geological Survey, Washington (1985).

[18] American Public Health Association (APHA). Standard Methods for Estimation of Water and Wastewater, 19th ed., American Water Works Association, Water Environment Federation, Washington, (1995).

[19] Chen M., Ma L. Q., Soil Science Society of American Journal 65(2) (2010) 491-499. 
[20] A. K. De, Environmental Chemistry, pp. 232-272, 4th ed., New Age International (P) Ltd., New Delhi, India (2002).

[21] The Environment (Protection) Rules (1986) Available at: http://www.cpcb.nic.in/GeneralStandards.pdf (assessed on November 2011).

[22] P. Daniszewski, International Letters of Chemistry, Physics and Astronomy 4 (2012) 112-118.

[23] E. Cyrania, P. Daniszewski, B. Draszawka-Bołzan, International Letters of Chemistry, Physics and Astronomy 5 (2012) 96-103.

[24] E. Cyraniak, P. Daniszewski, B. Draszawka-Bołzan, International Letters of Chemistry, Physics and Astronomy 5 (2012) 88-95.

[25] P. Daniszewski, R. Konieczny, International Letters of Chemistry, Physics and Astronomy 4 (2013) 91-97.

[26] P. Daniszewski, R. Konieczny, International Letters of Chemistry, Physics and Astronomy 4 (2013) 98-104.

[27] P. U. Singare, M. S. Talpade, D. V. Dagli, V. G. Bhawe, International Letters of Chemistry, Physics and Astronomy 8(2) (2013) 94-104

[28] P. U. Singare, M. S. Talpade, D. V. Dagli, V. G. Bhawe, International Letters of Chemistry, Physics and Astronomy 8(2) (2013) 105-112

[29] P. Daniszewski, International Letters of Chemistry, Physics and Astronomy 8(3) (2013) 269-278.

[30] P. Daniszewski, International Letters of Chemistry, Physics and Astronomy 8(3) (2013) 279-287.

[31] P. Daniszewski, International Letters of Chemistry, Physics and Astronomy 10(2) (2013) 218-226. 